\title{
Design and Optimization of Automatic Shifting Mechanism for the Tractor
}

\author{
Shiheng Sun, Huiting Shi \\ Automotive application engineering, Wuhan University of Technology, Wuhan 430070, China
}

\begin{abstract}
The stability of the shifting mechanism is the basis of the reliability of the automatic shift system. The gear shifting process of Taishan TG1804 tractor is hard and long. In order to solve this problem, we design a tractor automatic shift system and apply it to the tractor successfully. This paper designs a shifting mechanism, optimizes the shifting mechanism and dose the dynamic bench test. The test results prove that the optimized shifting mechanism is more reliable and more reasonable.
\end{abstract}

\section{Introduction}

With the improvement of mechanization in our country, the traditional agricultural production mode died out gradually, because it's low efficiency. Agricultural land has experienced three stages of development: dispersal, integration and extensive outsourcing. The reform of agricultural and the support of the country have greatly promoted the development of agricultural machinery industry.

The market of agricultural machinery industry continues to expand. With the increasing number of users, new requirements have been put forward for the agricultural machinery industry. The users require not only the products to be affordable, but also easy to operate. At present, most of the agricultural tractors use manual shift method in our country. The shift is timeconsuming and the laborious, especially for tractors with more gears. The drivers work at a hard environment, have to work a long time, need to change gears and operate the agricultural machinery frequently. The drivers are easy to get tired.

The application of automatic transmission in the tractor can complete the shift automatically, reduce the operating burden of the drivers greatly, and meet the needs of the users. We can optimize the design of the automatic shift system to control the additional cost within the acceptable degree of the user. Therefore, the application of automatic transmission in tractor is significant.

\section{Development of automatic transmission}

Automatic transmission of tractor mainly has Automatic Transmission (AT), Automatic Mechanical Transmission (AMT), and Continuously Variable Transmission (CVT).

\subsection{Automatic transmission}

Automatic Transmission mainly consists of hydraulic torque converter, planetary gear mechanism and automatic shift control system. Hydraulic torque converter changes the torque through the change of liquid moment of momentum, has a good ability to adjust and adapts the external load automatically, contributes to a smoothly starts of the tractor, prevents transmission from overload. However, when the engine is at a low speed, the transmission efficiency is very low, and the torque can not be changed, and the drive ratio can not be controlled accurately. As a result, AT is seldom used on tractors.

The application of AT in tractors firstly appeared in the late 1950s. The American Caterpillar company firstly used AT in its crawler tractors. At the same period, such as the series of crawler tractors of the Case industrial, industrial tractors of the German Fendt company, etc., have also used this transmission.

\subsection{Automatic mechanical transmission}

Automatic Mechanical Transmission is realized based on the traditional manual transmission by adding shifting mechanism, hydraulic (pneumatic or electric) power system and electronic control system. The structure of AMT is relatively simple, has a good inheritance of production, and has high transmission efficiency. However, due to the power interruption during shift, there is a shift shock, which affects the ride comfort.

The overseas researches on AMT start earlier and have more achievements. Eaton's SAMT system, Scania CAG system and Daimler's EPS system have a representative contribution to the start control of the tractor. Japanese Isuzu Motor Ltd, Germany ZF, Japan 
Nissan, France Renault and other companies promote the application of full automation AMT on tractors greatly.

Some universities in China have made great achievements in the research of tractor AMT. Tsinghua University has carried on the simulation experiments in the AMT clutch control aspect, and made a further research, realized the clutch control automatically. YTO Group Corporation and Henan University of Science and Technology develop different gear shifting strategy for different operation conditions together. Jilin University makes a further research on the clutch control strategy when starting and shifting, and formulates the optimum strategy of starting clutch control, and proposes the dynamic three parameter shift schedule.

\subsection{Continuously variable transmission}

The change of speed ratio of continuously variable transmission is continuous. CVT is different from traditional gearbox which has fixed axle. The transmission of power can be sustained without interruption. There are two types of CVT applied in tractors. One is the hydraulic-mechanical CVT which changes the speed ratio continuously by changing the diameter of the driven pulley. The transmission has a light weight, a small size, few components, a high transmission efficiency, a low fuel consumption. But the transmission ratio has a narrow range, and the belt is easy to damage and can not bear large loads. Another is composed of hydraulic pump and hydraulic motor named Hydro-static Transmission. Its main features are: speed can change continuously, can absorb the shift shock and prevent the tractors from overload, starting fast and soft, can adapt different agricultural machinery, can match with different engine. But the machining accuracy is high and the price is expensive.

Table 1. Advantages and disadvantages of different automatic transmissions

\begin{tabular}{|c|c|c|}
\hline AT & $\begin{array}{c}\text { Advantages } \\
\text { Mature technology } \\
\text { High shifting quality }\end{array}$ & $\begin{array}{c}\text { Low transmission } \\
\text { efficiency. }\end{array}$ \\
\hline AMT & $\begin{array}{c}\text { Simple structure } \\
\text { Low cost, } \\
\text { Low fuel consumption. }\end{array}$ & $\begin{array}{c}\text { Shift power interruption } \\
\text { Shift shock } \\
\text { Complex clutch control. }\end{array}$ \\
\hline CVT & $\begin{array}{c}\text { Continuous change of } \\
\text { speed ratio } \\
\text { Good shift quality }\end{array}$ & $\begin{array}{c}\text { complex structure } \\
\text { High cost }\end{array}$ \\
\hline
\end{tabular}

Due to the high cost of manufacture, the first application of hydraulic-mechanical CVT in 926Vario tractors of Fendt company started in 1996. At present, it's used in Agrotron TTV series of Deutz-Fahr company, Massey Ferguson company's 7400 series and John Deere company's 7R and 8R series abroad. Hydro-static transmission is mainly applied in small tractors, such as South Korea's Machindra 3510, New Holland Boomser 35, John deere3038E. The study on Hydro-static transmission started in 1970s in our country. Hydro-static transmission is mainly used in engineering and military vehicles. At present, the domestic study on hydro-static transmission is still in the prototype stage, has made some achievements. The research institutions are Henan University of Science and Technology, Jiangsu University, etc. The advantages and disadvantages of different automatic transmissions are shown in table 1.

\section{The design of shifting mechanism}

The test vehicle is TG1804 tractor with 16 gears in the gearbox. The tractor includes forward and reverse gears, 4 gears in the main transmission box, 4 gears in the secondary transmission. The main transmission box adopts synchronizer to change gears, and the secondary transmission uses meshing sleeve to change gears. We designed a new shift mechanism, and designed a clutch separation mechanism to realize the automatic shift in the main transmission. Figure 1 shows the modeling of the main transmission gear of TG1804 tractor.

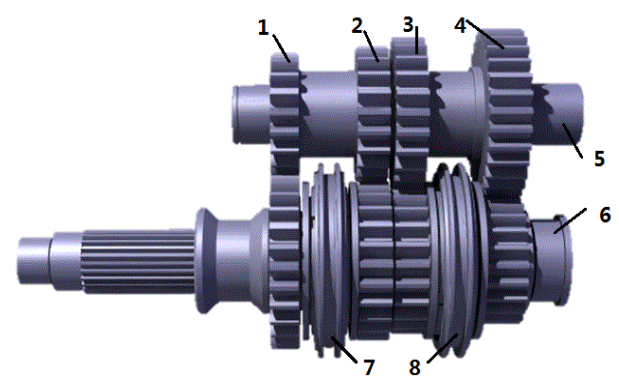

1-the 4th meshing gears, 2-the third meshing gears, 3-the second meshing gears, 4-the first meshing gears, 5-output shaft, 6-input shift, 7-3/4 synchronizer, 8-1/2 synchronizer.

Figure 1. The modeling of the main transmission gear.

\subsection{Determination of the gear shifting force}

To determine the gear shift force, we should determine the transmission ratio of each gear first. We need to determine the angular speed difference when the gears are shifted at a given engine speed. And we know when the engine speed is $2000 \mathrm{rad} / \mathrm{s}$, the engine has a maximum power. When the engine speed is $1500 \mathrm{rad} / \mathrm{s}$, it has a maximum torque. And we know the gear ratio of the transmission. The angular speed difference when upshift or downshift is shown in table 2. $\Delta \omega$ means the angular speed difference when shift.

Table 2. The angular apeed difference when shift

\begin{tabular}{|c|c|c|c|c|c|c|}
\hline & $1-2$ & $2-3$ & $3-4$ & $4-3$ & $3-2$ & $2-1$ \\
\hline$\Delta \omega(\mathrm{rad} / \mathrm{s})$ & 28.00 & 23.23 & 22.89 & 19.32 & 19.67 & 24.93 \\
\hline
\end{tabular}

In the process of shift, the inner cone of the lock ring contacts the outer cone of the gear to be engaged. Force analysis of the gear to be engaged is shown in figure 2 . According to the conservation of energy, the formula 1 should be satisfied when complete the synchronization at a given time [4]. 


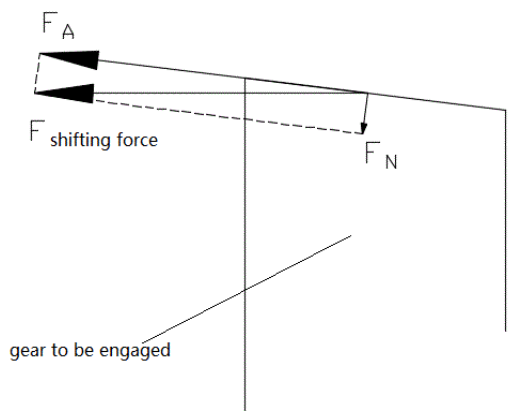

Figure 2. Force analysis of the gear to be engaged.

$$
J \Delta \omega \leqslant F R_{1} \mu t / \sin \alpha
$$

The $\mathrm{F}$ is the shift force, and other parameters are shown in table 3 . When the given synchronization time is $0.2 \mathrm{~s}$, in order to meet all gear shifting requirements, we need to take the maximum angular speed difference as $\Delta$ $\omega$, so the $\Delta \omega$ takes the angular speed difference when up-shift from 1 gear to 2 gear, and the angular speed difference is $28 \mathrm{rad} / \mathrm{s}$.

Table 3. The meaning and value of the parameter

\begin{tabular}{|c|c|c|}
\hline $\begin{array}{c}\text { Symbol } \\
\mathrm{s}\end{array}$ & Meaning & Value \\
\hline $\mathrm{J}$ & Input moment of inertia & $0.263 \mathrm{~kg} \cdot \mathrm{m}^{2}$ \\
\hline$\Delta \omega$ & $\begin{array}{c}\text { Angular velocity difference when } \\
\text { shifting }\end{array}$ & $28 \mathrm{rad} / \mathrm{s}$ \\
\hline $\mathrm{t}$ & Synchronization time & $0.2 \mathrm{~s}$ \\
\hline $\mathrm{R}_{1}$ & $\begin{array}{c}\text { Average working radius of friction } \\
\text { cone }\end{array}$ & $54.63 \mathrm{~mm}$ \\
\hline$\mu$ & friction coefficient & 0.1 \\
\hline$\alpha$ & the angle of friction cone & $7^{\circ}$ \\
\hline
\end{tabular}

\subsection{Schematic diagram of shift}

According to the requirements of the company, we choose pneumatic shift. The maximum pressure that the tractor can provide is $0.8 \mathrm{Mpa}$. The displacement of the synchronizer is 11 millimeters when the shift fork shaft moves from neutral palace to gear palace. A shifting fork shaft has three positions: first (or third) gear, second (or 4 th) gear and neutral position.

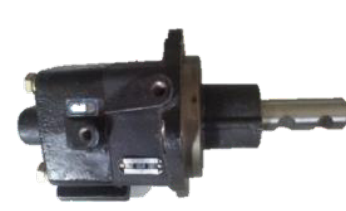

(a)

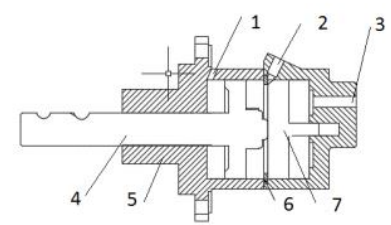

(b)
1-A inlet, 2-B inlet, 3-C inlet, 4- piston rod, 5-cylinder block, 6- piston rod's right limiting ring, 7 limit piston,

Figure 3. Shift cylinder.

We choose the Fastre shifting cylinder, as shown in Figure 3 (a). The piston rod has three fixed positions by controlling the inlet of the cylinder. As shown in Figure 3 (b), there is a limiting piston inside the cylinder. When A inlet intakes air, the piston rod will move to the right limit position, B inlet intakes air, the piston rod moves to the left limit position, A, C inlet intake air at the same time, limiting piston moves to left limiting position, the piston rod moves to the neutral position, the pressure of $\mathrm{C}$ inlet is greater than the $\mathrm{A}$ inlet.

The diameter of the shift cylinder bore is $76 \mathrm{~mm}$, and the diameter of the piston rod is $25 \mathrm{~mm}$. After calculation, the theoretical value of the shift gas pressure is $0.2 \mathrm{Mpa}$. And we take $0.22 \mathrm{Mpa}$ as the actual value. In order to have a neutral position, the air pressure at the $\mathrm{C}$ inlet is greater than the $\mathrm{A}$ inlet, so the pressure at the $\mathrm{C}$ inlet is $0.3 \mathrm{Mpa}$. Pressure relief valve regulate pressure at $0.35 \mathrm{Mpa}$, the pressure reducing valve 1 regulate pressure at $0.3 \mathrm{Mpa}$, and the pressure reducing valve 2 regulate pressure at $0.22 \mathrm{Mpa}$. We choose two 3 dimensional 5 way solenoid valve and two 2 position 3 way solenoid valve. The schematic diagram of shift is shown in figure 4, the pressure generated by the air pump is stable at $0.35 \mathrm{Mpa}$ after overflow pressure relief valve. The air is divided into two directions, one flow to $\mathrm{A}$ and $\mathrm{B}$ inlet, another flow to $\mathrm{C}$ inlet. The pressure at $\mathrm{A}$ and $\mathrm{B}$ inlet is $0.22 \mathrm{Mpa}$, and the pressure at the $\mathrm{C}$ inlet is $0.3 \mathrm{Mpa}$. The control program controls the opening and closing of the electromagnetic valve, and realizes the opening and closing of the air inlet to meet the shift requirements.
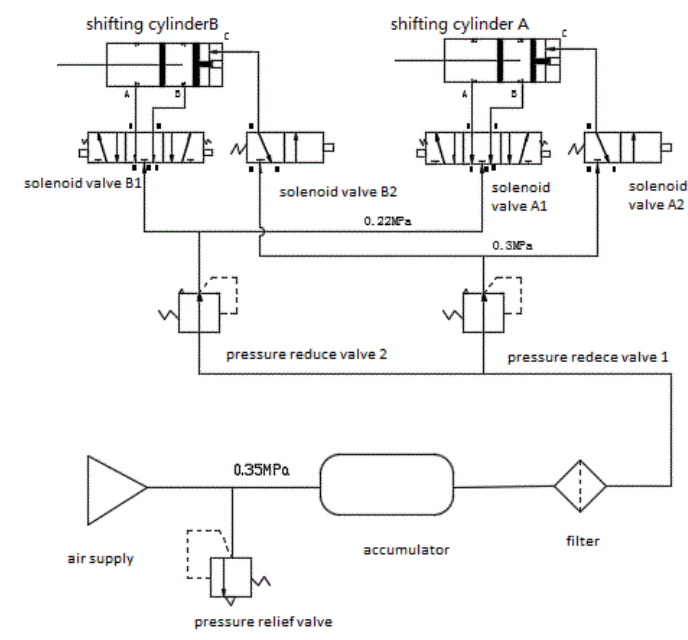

Figure 4. The schematic diagram of shift.

\subsection{Shifting mechanism design}

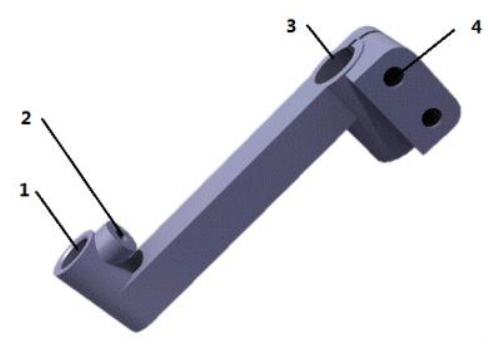

1-Shifting fork shaft marching hole, 2- set screw hole, 3 cylinder piston rod matching hole, 4 - bolt holes;

Figure 5. The model of connecting part.

The three-dimensional model of the connecting part is shown in figure 5 . The connecting part is connected with the shifting fork shaft and the cylinder piston rod respectively. The number 1 is the matching hole of the 
fork shaft, number 2 is the set screw hole, the connecting part is fixed with the shifting fork shaft through a set screw. Number 3 is the matching hole of the cylinder piston rod, through two M12 bolts to achieve the solid connection between the connecting part and the cylinder piston rod.

The assembly diagram of the pneumatic shifting mechanism is shown in figure 6. By controlling the opening and closing of the electromagnetic valve, we can control the opening and closing of the corresponding intake and exhaust ports, and control the movement of the piston rod of the cylinder. Through the connecting part, the piston rod drives the fork shaft to move. Control the cylinder to realize the shift operation.

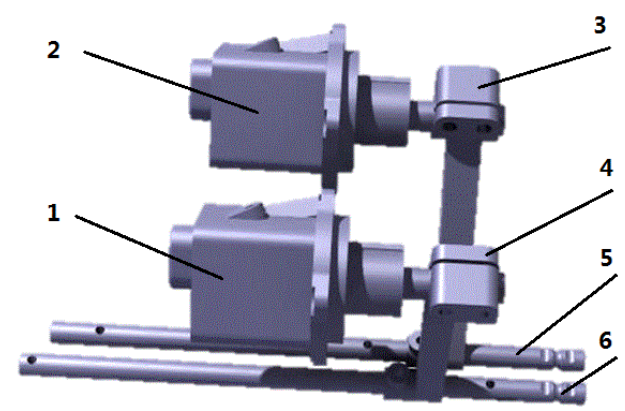

1- 3/4 shift cylinder, 2 -1/2 shift cylinder, $3-1 / 2$ connecting part, 4- 3/4 connecting part, 5- 1/2 shift fork shaft, 6-3/4 shift fork shaft.

Figure 6. Assembly of pneumatic shift shifting mechanism.

\subsection{The problems}

Because the piston rod and the shifting fork move in the same direction, so the parallelism tolerance of the two holes of the connecting part is small, and it leads to higher machining accuracy. If the parallel tolerance does not meet the design requirements, the required shift force increase, and the wear of the gearbox will increase. There will be movement interference between the cylinder piston rod and fork. In extreme condition, we can not shift. Because the upper cover's space is small, it is hard to install. After installation, the physical drawing is shown in figure 7.

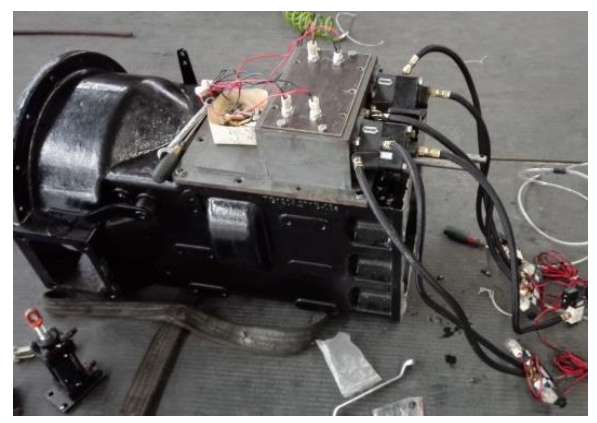

Figure 7. The physical drawing.

After the installation, we did the dynamic bench test and debugged the program, and the reliability of the shifting mechanism was tested. Under the engine idling speed and the wheel suspended, we shift 4 hours every day for 5 days, a total of 6000 times shifting, and record the 400 groups of data about the total gear shift time and shift fork shaft movement time. These are several times we failed to upshift from first gear to second gear. When raising the inlet pressure, it does not happen anymore. The analysis result is the connecting parts do not meet the parallel tolerance. There is interference between the shifting fork shaft and the piston rod.

\section{Optimization of shifting mechanism}

The connecting part of the original design has a high machining accuracy, and it is hard to install. When the machining errors existed it will increase the shift force and the shift time. The connecting part can not meet the requirement to change gears when the machining errors reach a certain degree.

\subsection{The design of the shifting mechanism}

After optimization, the connecting part is changed into two parts. This design avoids the high machining accuracy. The optimized connecting parts reduce the quality by $0.736 \mathrm{~kg}$ compared with the original designed part. The cost increases little because of the reduction of mass and machining accuracy. It is convenient to install the new connecting parts. The force condition of the shifting mechanism gets better. The designed 3D model and assembly model of the shifting mechanism are shown in Figure 8
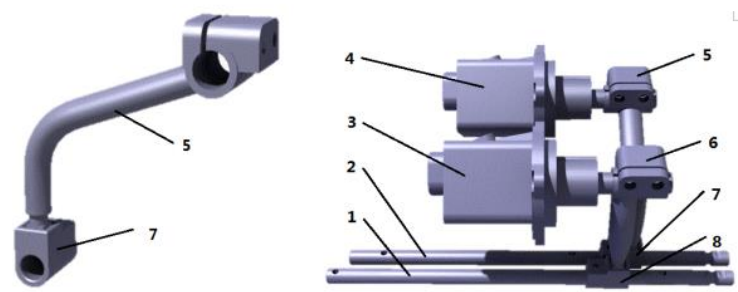

1-3/4 shift fork shaft; 2-1/2 shift fork shaft; 3-3/4 cylinder; 4$1 / 2$ cylinder; $5-1 / 2$ connecting part; $6-3 / 4$ connecting part; 7-1/2 blocks; 8-3/4 blocks

Figure 8. 3D Model and assembly model of the shifting mechanism.

\subsection{Strength analysis}

The established 3D model is imported into ANSYS. The material for the connecting parts is 45 steel. The connection is restrained according to the actual condition. In the process of shifting, the force of the $1 / 2$ gear shift is more complicated than that of the $3 / 4$, so we analysis the force of the $1 / 2$ gear shift. The direction of force is determined by the weak force region of the block. And the shift force is $1000 \mathrm{~N}$. The connecting parts is tetrahedral mesh, the block is hexahedral mesh. The mesh density will be increased if the force of the region of the part is weak. The constraints and loads, mesh and the force of the connecting parts are shown in figure 9.

We can see that the maximum compressive stress is $338 \mathrm{Mpa}$, which is far less than the strength limit 598Mpa of the selected material. The designed connecting parts can meet the reliability requirements. 


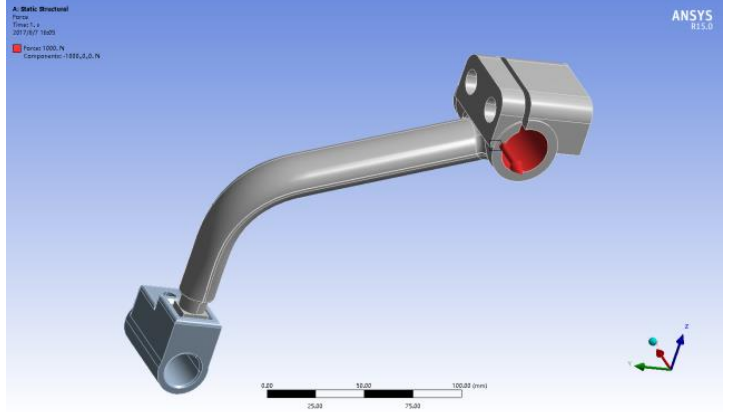

(a)

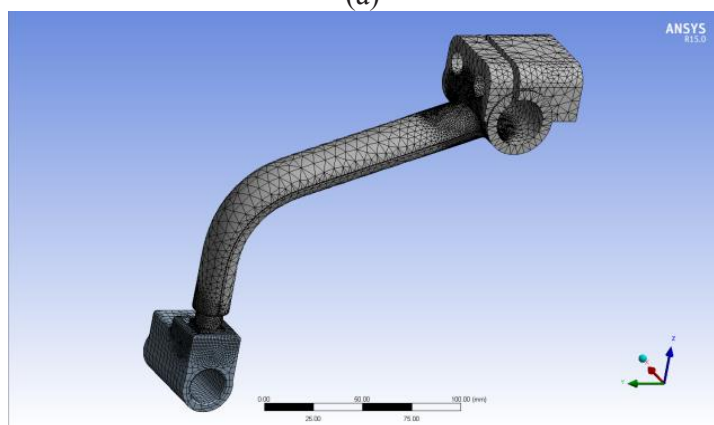

(b)

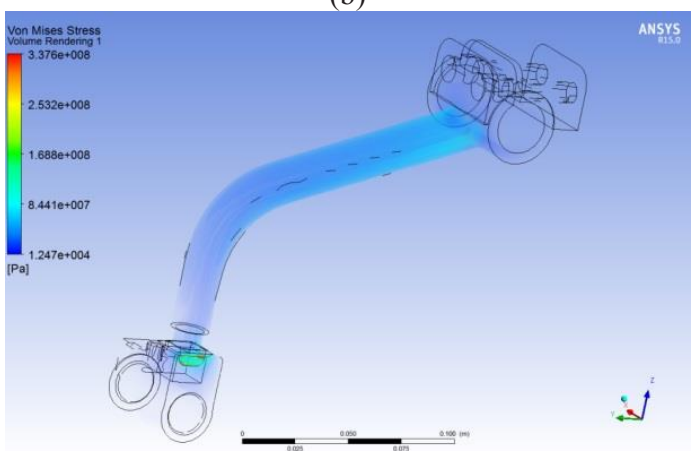

(c)

Figure 9. Strength analysis of the connecting parts.

\subsection{Bench test}

The new designed parts are shown in figure 10 .

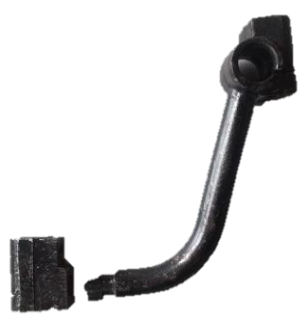

Figure 10. New contecting parts.

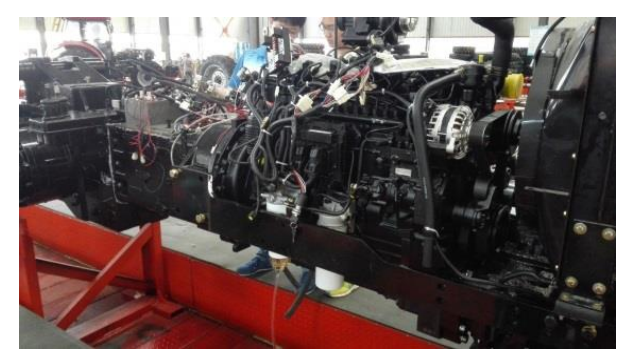

Figure 11. Bench test.
Install the newly designed connecting parts on the transmission and do reliability experiment. The bench test is shown in figure 11. The test condition is the same with old connecting parts include the pressure, engine speed. The times of the shift experiment is 6000 , and the number of data acquisition is 400 .

There is no fault happens after 6000 shift operation. The new designed shifting mechanism is reliable. Process the data and obtain the shifting time comparison after optimization. The comparison of the shifting fork shaft moving time after optimization is shown in figure 12 .

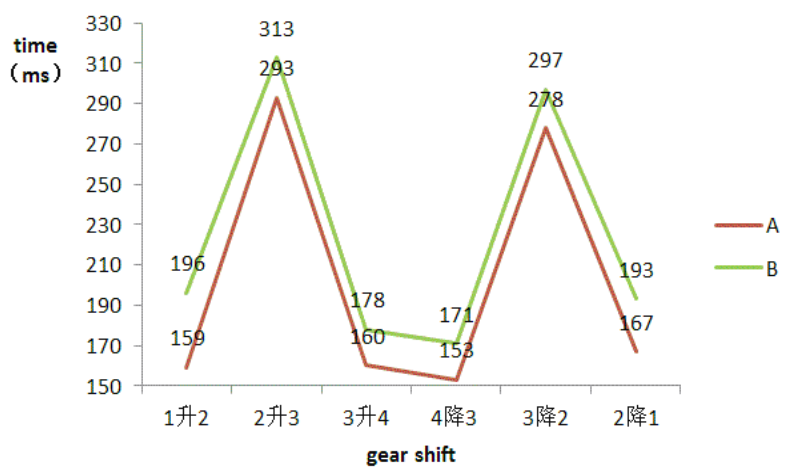

A means the shifting fork shaft moving time after optimization $\mathrm{B}$ means the shifting fork shaft moving time before optimization

Figure 12. Comparison after optimization.

\subsection{Experimental result analysis}

When upshift from second gear to third gear or downshift from third gear to second gear, the shifting process is longer than other gear shift. This phenomenon accords with the actual situation. Because one shifting fork shaft has to arrive at a neutral position, then another shifting fork shaft began to move. And in this process, the number of the working solenoid valve is double than other gear shifting. So the shift process is long. The change trend of the switching time of other gears is same as that of theoretical synchronization. The larger the angular velocity difference of gear shifting is, the longer the movement time of the shifting fork shaft in the shift process.

Under the same shift condition, through the comparison of the shift time and reliability between the new and old parts, it can be found that after optimization, the shift time is shorter, and the shift is faster.

\section{Conclusions}

In this paper, we designed an automatic shift system and applied it to the TG1804 tractor successfully. We designed a new shifting mechanism because the shift failure caused by the original shifting mechanism. We did the bench test for the shift system and got enough experiment data. The newly designed shifting mechanism meets the strength requirement after simulated analysis. The test results show that the newly designed shifting mechanism has better reliability and a shorter shift time compared with the original shifting mechanism. 


\section{References}

1. Kulkarni M, Shim T, Zhang Yi. Shift dynamics and control of dual-clutch transmissions. Mechanism and Machine Theory, 2007, 48: 168-182

2. Tang Xuemei. The script simulation of shifting process in transmission system. Mechanic Automation and Control Engineering. Wuhan, 2010: 3226-3228.

3. Lovas L, Play D, Marialigeti J, et al. Mechanical behaviour simulation for synchronous mechanism improvements. Automobile Engineering: 2006, 22: 17-19.

4. Hoshino H. Simulation on synchronization mechanism of transmission gearbox. International ADAMS User Conference, 1998.

5. Häggström D. Development of a program for calculating gearbox synchronization. Sweden: Luleå University of Technology, 2011.

6. T. Nitulescu, S. Talu, Applications of descriptive geometry and computer aided design in engineering graphics, Cluj-Napoca, Risoprint Publishing house, Romania, 2001 